Email: population@pncampus.edu.np

eJournal Site: http://ejournals.pncampus.edu.np/ejournals/ajps/

\title{
Prevalence and Determinants of Anaemia among Women aged 15-49 in Nepal: A Trend Analysis from Nepal Demographic and Health Surveys from 2006 to 2016
}

\author{
Devaraj Acharya \\ Bhairahawa Multiple Campus, TU, Rupandehi, Nepal \\ Ramesh Adhikari \\ Mahendra Ratna Campus, TU, Kathmandu, Nepal \\ Padam Simkhada
}

School of Human and Health Sciences, University of Huddersfield, UK

Corresponding Author \& Email

Devaraj Acharya; Email: devaraj.acharya@bmc.tu.edu.np

Article History

Submitted 21 December 2021; Reviewed 26 December 2021; Accepted: 31 December 2021 DOI: https://doi.org/10.3126/ajps.v1i1.43593

\section{Copyright Information: \\ Copyright 2022@ The Author(s). \\ The journal is licensed under a \\ Creative Commons Attribution- \\ ShareAlike 4.0 International \\ License. \\ (c) ${ }_{\mathrm{BY}}$ (i) \\ Published by \\ Department of Population Studies \\ Prithvi Narayan Campus \\ Tribhuvan University \\ Pokhara, Nepal}

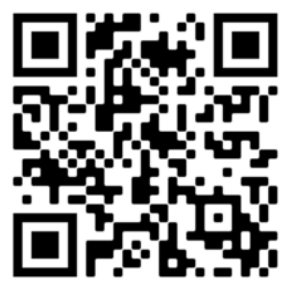

Scan to Access eJournal

\begin{abstract}
Anaemia remains one of the major health problems throughout the world and is most common in underdeveloped or developing countries like Nepal. Most of the studies have presented and analysed the situation on a particular time basis that could be by chance. The paper intended to assess the trends of anaemia prevalence amongst reproductive-age women throughout the decade using nationally representative data. The study used the data from recent three Nepal Demographic and Health Surveys (NDHS) 2006, 2011, and 2016. More than one third (36\%, 35\%, and $41 \%$ in NDHS 2006/2011/2016 respectively) of women of reproductive age were anaemic. Data showed inconsistent trends of anaemia prevalence among the surveys years. The situation of anaemia has not been improved. It was even worse in the latest NDHS 2016. Policymakers should reconsider, re-evaluate, and revise the intervention programmes applied to reduce anaemia.
\end{abstract}

Keywords: Haemoglobin level; nutritional status; prevalence of anaemia; status of women; women of reproductive age 


\section{Prevalence and Determinants of Anaemia among Women aged 15-49 in Nepal}

\section{Introduction}

Anaemia is one of the major public health problems globally and the second leading cause of disability among pregnant women (World Health Organization, 2016). Poor maternal health is also associated with low birth outcomes including maternal morbidity and mortality (Okawa et al., 2019). Anaemia is defined as less than $12.0 \mathrm{~g} / \mathrm{dl}$ for non-pregnant and $11.0 \mathrm{~g} / \mathrm{dl}$ haemoglobin level for pregnant women (Ministry of Health et al., 2017) however definition varies in terms of severity, sex, living condition, and status of women including age (Ford et al., 2020; Miles et al., 2019). Lower concentration of the haemoglobin in the blood affects the circulation of oxygen throughout the body including the brain which limits the maternal and birth outcomes, leads to high morbidity and mortality among mothers and neonates, reduces the working ability and productivity including learning capacity (Harding et al., 2017). Anaemia depresses the immune system and increases the chances of morbidity both in mothers as well as neonates (Abusharib, 2019). It further influences cognitive and intellectual development, socio-economic growth, gross domestic products, and ultimately delay achieving developmental targets including Sustainable developing Development Goals [SDG](Department of Health Services, 2019).

Anaemia prevalence is common around the globe but most prevalent in developing countries. Prevalence of anaemia was recorded higher in the South Asian and African continent than in other countries throughout the world (Ajepe et al., 2020). Global estimation indicated that three out of ten (29\%) of non-pregnant women and more than one third (38\%) were anaemic (Herzog et al., 2019; Kay et al., 2019). It is estimated that nearly half a billion of women from reproductive age are affected by anaemia (Wemakor, 2019). Nearly four out of ten (38.5\%) women of reproductive age [WRA] were anaemic in Nepal. SDG number two has a specific target of reducing anaemia prevalence among WRA by less than one per cent by 2030 (National Planning Commission, 2015).

There are numerous and complex factors that can cause anaemia. Low intake of iron-rich foods together with poor bioavailability, chronic infection, malaria and intestinal helminths, and higher requirement related to menstruation lead to iron deficiency(Ampiah et al., 2019; Jamnok et al., 2020).Educational status, age, access to healthcare, socio-economic status, frequency of pregnancy, availability and consumption of nutrients/diet, and place of residence are identified as associated factors for being anaemic(Sharma et al., 2020). Anaemia affects individuals in the different periods of the life cycle but is most common in lactating mothers, pregnant women and adolescent girls as well (Ayensu et al., 2020; Williams et al., 2020). Nearly one-fifth of the total maternal deaths are resulted directly due to anaemia. Moreover, another 20 per cent of deaths are caused due to anaemia related causes such as sepsis, haemorrhage or other indirect causes of anaemia (Neogi et al., 2019). Besides these, anaemia is responsible for serious health consequences during and after pregnancy not only for mothers but for babies too (Grover et al., 2020).

Various programmes are being implemented to reduce the prevalence of anaemia in Nepal. Deworming programme, outreach clinic at the community level, iron supply free of cost are some examples. Despite these efforts by the government, the proportion of anaemic women have not decreased as per the anticipation throughout the decade in Nepal(Ford et al., 2020). Many studies have been conducted in the field of nutritional status of women including anaemia but we could not find any study focusing on trend analysis of anaemia among WRA (15 to 49 years). Therefore, the study aimed to assess the trend of anaemia prevalence among WRA (15-49 years). 


\section{Prevalence and Determinants of Anaemia among Women aged 15-49 in Nepal}

\section{Methods}

\section{Data sources and characters}

The study uses secondary data from Nepal Demographic and Health Survey [NDHS] conducted in 2006, 2011, and 2016. The NDHS was the national representative periodic survey conducted every five years. The main objectives of the NDHSs were to provide, update to date, reliable, and accurate information about demographic and health-related data which would be essential for policymaking, programme planning, formulation of monitoring and evaluation tools for improving maternal and child healthcare services in Nepal(Gautam et al., 2019; Ministry of Health et al., 2017).

The sample was taken from two stages. First, it involved selecting cluster based on probability proportional to size from the national sample frame on the basis of the latest national census and households survey2001 for NDHS 2006 and NDHS 2011, and of national census 2011 for NDHS 2016(Ministry of Health et al., 2017; Ministry of Health and Population (MOHP) [Nepal] et al., 2007, 2012). Second, systematic sampling was followed from the list of households as created in NDHS clusters. The sample was taken in two stages for NDHS 2006 and NDHS 2011(Ministry of Health and Population (MOHP) [Nepal] et al., 2007, 2012) but NDHS 2016 used two stages in Gaupalika (rural areas) and three stages in Nagarpalika (urban areas) (Ministry of Health et al., 2017). Some changes were made in NDHS 2016 such as provinces replacing developmental regions, rural-urban setting, municipal boundaries due to how the political map has been changed.

\section{Measures}

Non-pregnant women who had less than $12.0 \mathrm{~g} / \mathrm{dl}$ (gram per decilitre) haemoglobin level and pregnant women who had less than $11.0 \mathrm{~g} / \mathrm{dl}$ haemoglobin level were considered anaemic and analysed accordingly. For non-pregnant women, 10.0 to $11.9,7.0$ to 9.9 , and less than $7.0 \mathrm{~g} / \mathrm{dl}$ haemoglobin levels were classified as 'mild', 'moderate', and 'severe' anaemia respectively. Similarly, haemoglobin levels of 10.0 to 10.9, 7.0 to 9.9, and less than 7.0 g/dl were categorized as 'mild', 'moderate', and 'severe' anaemia respectively for pregnant women (Ministry of Health et al., 2017). A survey questionnaire was used for collecting the household's and individual's information. Haemoglobin was analysed using a HemoCue analyser which was a portable batteryoperated device. Some variables like age, age at marriage, number of children, literacy status, religion, dwelling status/setting, employment status, wealth category, autonomy on decision making, smoking habit, and media exposure were analysed as per the study objective and the literature available for interpretation. The age of women was further classified into three categories as less than 25 years, 25 to 34 years, and more than 35 years.

There were three issues assessed for women's autonomy in decision making mostly in household: first, autonomy on their own healthcare; second, autonomy on household major goods/asset purchases; and third, autonomy on visiting their relatives or family. Women's autonomy on all these three issues was considered as 'high autonomy', autonomy on any two of these was considered as 'moderate autonomy' and none of these as 'no autonomy'. In the case of wealth status, wealth quintiles I and II have been merged as 'poor' quintiles III as 'middle' and quintiles IV and V as 'rich' categories. Similarly, exposure to mass/public media at least once a week was considered as 'high exposure' less than once a week as 'low exposure' and no access to mass media as 'no exposure' for newspaper, radio, and TV. 


\section{Prevalence and Determinants of Anaemia among Women aged 15-49 in Nepal}

\section{Statistical analysis}

For the analysis of the data, IBM SPSS Statistics 22 was used. Prevalence of anaemia is defined as the per cent of women who had anaemia (less than $12.0 \mathrm{~g} / \mathrm{dl}$ and $11.0 \mathrm{~g} / \mathrm{dl}$ haemoglobin levels for non-pregnant and pregnant women respectively). Descriptive (frequencies and percentage), bivariate (cross-section with chi-square test), and multivariate analysis (binary logistic regression) were performed to present the data and results. We performed univariate analysis and bivariate analysis separately but for multivariate analysis, all data have been merged and analysed accordingly. The acceptable margin of error was set at five per cent and confidence intervals were set at 95 per cent with $p$-values which considered less than 0.05 as significant for differences.

\section{Ethical consideration}

Nepal Health Research Council [NHRC], Kathmandu, and IFC International Review Board, Maryland reviewed and approved the survey protocol (Ministry of Health et al., 2017; Ministry of Health and Population (MOHP) [Nepal] et al., 2007, 2012). Respondents were informed about study objectives and requested for voluntary participation. Written consent was taken prior to the interview as well as haemoglobin testing and in the case of minor [age between 15 to 17 years], the consent was taken from parents or the adults who were responsible to take care of them. Data and samples were taken from the individuals who agreed to participate. Women were referred to concerned health facilities for follow-up care if less than $9.0 \mathrm{~g} / \mathrm{dl}$ and $7.0 \mathrm{~g} / \mathrm{dl}$ haemoglobin levels were observed for pregnant and non-pregnant women respectively. The survey followed the ethical guidelines for health-related research made by NHRC (Nepal Health Research Council, 2011).

\section{Results}

\section{Socio-demographic characteristics of WRA}

The study included 10647, 6088, and 6414 sample from NDHS 2006, NDHS 2011, and NDHS 2016 respectively. Therefore, a total of 23149 data were analysed to find out the determinants of anaemia in women. There was a higher number of samples in NDHS 2006 compared to other NDHSs. The educational status of women has been gradually increasing towards secondary and higher education while the proportion of illiterate women was gradually decreasing [Table 1]. In the same way, the urban population was also in increasing trend consequently rural population in decreasing trend. Interestingly, proportion of currently working women was in decreasing trend despite different governmental efforts to empower women including various reservation facilities in the formal sectors. The proportion of women with high autonomy increased in NDHS 2011 compared to 2006 but declined in 2016. Exposure to the radio at least once a week was decreasing whereas exposure to TV at least once a week was in increasing trend. Data also showed that women are interested to watch TV compared to listening to the radio during the last decade.

Table 1

General characteristics (\%) of participants (WRA)

\begin{tabular}{llcccc}
\hline Variables & Category & $\begin{array}{c}\text { NDHS } \\
\mathbf{2 0 0 6}\end{array}$ & $\begin{array}{c}\text { NDHS } \\
\mathbf{2 0 1 1}\end{array}$ & $\begin{array}{c}\text { NDHS } \\
\mathbf{2 0 1 6}\end{array}$ & Pooled \\
\hline \multirow{4}{*}{ Anaemia level } & Severe & 0.4 & 0.3 & 0.3 & 0.4 \\
& Moderate & 6.4 & 5.7 & 7.0 & 6.4 \\
& Mild & 29.4 & 28.9 & 33.5 & 30.4 \\
& Not anaemic & 63.8 & 65.0 & 59.2 & 62.8 \\
\hline
\end{tabular}


Prevalence and Determinants of Anaemia among Women aged 15-49 in Nepal

\begin{tabular}{|c|c|c|c|c|c|}
\hline \multirow{3}{*}{ Age group } & $<25$ years & 41.1 & 39.8 & 37.7 & 39.4 \\
\hline & $25-34$ & 28.8 & 30.3 & 30.6 & 30.0 \\
\hline & $\geq 35$ years & 30.1 & 29.9 & 31.7 & 30.6 \\
\hline \multirow{4}{*}{$\begin{array}{l}\text { Age at marriage, } \\
\text { cohabitation }\end{array}$} & Less than 15 & 4.0 & 8.1 & 11.1 & 8.0 \\
\hline & $15-17$ & 11.9 & 28.5 & 43.4 & 28.8 \\
\hline & $18-20$ & 7.9 & 18.8 & 28.8 & 19.1 \\
\hline & 21 and above & 76.2 & 44.6 & 16.7 & 44.2 \\
\hline \multirow{6}{*}{$\begin{array}{l}\text { Number of children } \\
\text { borne }\end{array}$} & None & 27.6 & 29.8 & 28.6 & 28.7 \\
\hline & One & 12.6 & 13.4 & 16.1 & 14.2 \\
\hline & Two & 17.1 & 19.7 & 21.7 & 19.6 \\
\hline & Three & 14.4 & 15.2 & 14.9 & 14.9 \\
\hline & Four & 10.3 & 9.7 & 8.8 & 9.6 \\
\hline & Five or more & 18.0 & 12.1 & 9.8 & 13.0 \\
\hline \multirow{3}{*}{ Education } & No education & 53.1 & 39.8 & 33.3 & 41.4 \\
\hline & Primary & 17.6 & 17.4 & 16.7 & 17.2 \\
\hline & $\begin{array}{l}\text { Secondary or } \\
\text { above }\end{array}$ & 29.3 & 42.8 & 50.0 & 41.3 \\
\hline \multirow{4}{*}{ Religion } & Hindu & 85.1 & 84.2 & 85.8 & 85.1 \\
\hline & Buddhist & 8.6 & 8.8 & 5.1 & 7.4 \\
\hline & Islam & 3.6 & 3.7 & 5.0 & 4.1 \\
\hline & Kirat/Christian & 2.6 & 3.3 & 4.1 & 3.4 \\
\hline \multirow{2}{*}{ Place of residence } & Urban & 15.6 & 14.4 & 62.8 & 31.9 \\
\hline & Rural & 84.4 & 85.6 & 37.2 & 68.1 \\
\hline \multirow{2}{*}{ Currently working } & No & 28.9 & 40.0 & 43.1 & 37.8 \\
\hline & Yes & 71.1 & 60.0 & 56.9 & 62.2 \\
\hline \multirow{3}{*}{ Wealth index } & Poor & 37.4 & 35.6 & 36.6 & 36.5 \\
\hline & Middle & 20.5 & 20.5 & 20.2 & 20.4 \\
\hline & Rich & 42.1 & 43.9 & 43.3 & 43.1 \\
\hline \multirow{3}{*}{$\begin{array}{l}\text { Women's autonomy } \\
\text { in household } \\
\text { decision }\end{array}$} & No autonomy & 45.1 & 42.0 & 44.3 & 43.8 \\
\hline & $\begin{array}{l}\text { Moderate } \\
\text { autonomy }\end{array}$ & 22.9 & 23.5 & 26.7 & 24.5 \\
\hline & $\begin{array}{l}\text { High } \\
\text { autonomy }\end{array}$ & 32.0 & 34.5 & 28.9 & 31.8 \\
\hline \multirow{2}{*}{ Smoking } & No & 80.4 & 86.7 & 91.6 & 86.6 \\
\hline & Yes & 19.6 & 13.3 & 8.4 & 13.4 \\
\hline \multirow{3}{*}{$\begin{array}{l}\text { Exposure to } \\
\text { newspaper }\end{array}$} & No exposure & 68.5 & 65.1 & 69.6 & 67.7 \\
\hline & Low exposure & 21.2 & 22.3 & 21.7 & 21.8 \\
\hline & High exposure & 10.3 & 12.6 & 8.7 & 10.5 \\
\hline \multirow{3}{*}{ Exposure to radio } & No exposure & 10.4 & 18.8 & 43.2 & 24.9 \\
\hline & Low exposure & 29.1 & 37.0 & 29.1 & 31.9 \\
\hline & High exposure & 60.5 & 44.2 & 27.7 & 43.2 \\
\hline \multirow{3}{*}{ Exposure to TV } & No exposure & 28.4 & 25.5 & 28.8 & 27.5 \\
\hline & Low exposure & 33.5 & 27.1 & 20.9 & 26.8 \\
\hline & High exposure & 38.1 & 47.4 & 50.3 & 45.7 \\
\hline Total & Number (\%) & 10647(100) & $6088(100)$ & 6414(100) & $23149(100)$ \\
\hline
\end{tabular}

\section{Prevalence of anaemia among WRA}

During the decade of 2006 to 2016, there was a minor change in the proportion of women having severe anaemia from 0.4 to 0.3 per cent. However, the proportion of 


\section{Prevalence and Determinants of Anaemia among Women aged 15-49 in Nepal}

women having moderate anaemia was in increasing trend i.e. seven per cent in 2016 compared to $2006(6.4 \%)$. Similarly, the rate of mild anaemia was also increasing i.e.33.5 in 2016 from 29.4 per cent in 2006 [Figure 1]. Surprisingly, despite various efforts by the government and other sectors to control anaemia, 41 per cent of the women had some kind of anaemia in the survey of 2016 which was a five per cent increment over the period of 10 years.

\section{Figure 1}

Prevalence of anaemia among WRA [15-49 years]

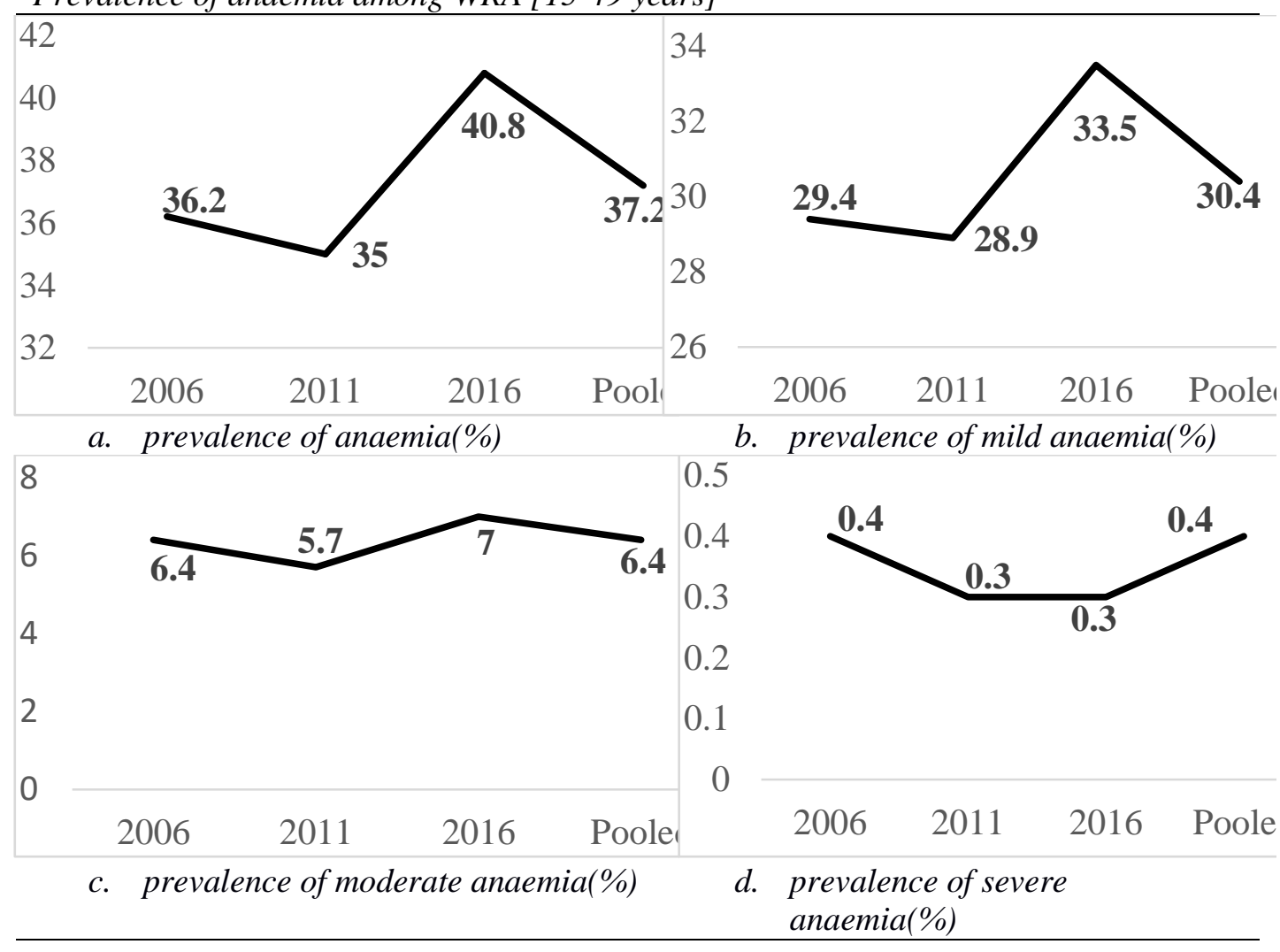

\section{Association of background characteristics of women and prevalence of anaemia}

Despite several programmes which have been launched to promote women's health status, it is depressing to note that the prevalence of anaemia, remained static or even worse throughout the decade. The NDHS 2016 recorded 41 per cent anaemic women, compared to 36 per cent in NDHS 2006. The proportion of anaemic women was in increasing trend in all age groups of the women during the decade of 2006 to 2016.Prevalence of anaemia had a significant association with age group and age at marriage in the years 2006 and 2016 [Table 2]. Interestingly, women having a primary level of education had a low level of anaemia prevalence compared to women having no education or higher than primary education. In regards to religion, Muslim women had a higher anaemia prevalence compared to women of other religions $(\mathrm{p}<0.001)$.

Rural women were more prone to be anaemic compared to the women who lived in urban areas. Similarly, the working condition of women was also significantly associated with the prevalence of anaemia. The women who had paid jobs were less vulnerable to have anaemia compared to jobless women $(\mathrm{p}<0.001)$. Similarly, women having middle-level wealth status were more anaemic than poor and rich women 


\section{Prevalence and Determinants of Anaemia among Women aged 15-49 in Nepal}

$(\mathrm{p}<0.01)$. But, the prevalence of anaemia was in increasing trend among the women who had rich wealth status $(\mathrm{p}<0.01)$. Women's autonomy was significantly associated with the prevalence of anaemia in NDHS 2006 and $2011(\mathrm{p}<0.001)$ but not in the NDHS 2016.

Table 2

Prevalence of anaemia in women by background characteristic

\begin{tabular}{|c|c|c|c|c|c|c|c|c|c|}
\hline \multirow{2}{*}{$\begin{array}{l}\text { Variables and } \\
\text { category }\end{array}$} & \multicolumn{3}{|c|}{ NDHS 2006} & \multicolumn{3}{|c|}{ NDHS 2011} & \multicolumn{3}{|c|}{ NDHS 2016} \\
\hline & $\begin{array}{l}\mathrm{No}(\% \\
)\end{array}$ & Yes(\% & Total & $\begin{array}{l}\operatorname{No}(\% \\
)\end{array}$ & Yes(\% & $\begin{array}{l}\text { Tota } \\
\text { l }\end{array}$ & $\begin{array}{l}\text { No(\% } \\
\text { ) }\end{array}$ & Yes(\% & $\begin{array}{l}\text { Tota } \\
\text { l }\end{array}$ \\
\hline Age group & $* * *$ & & & $* *$ & & & $* * *$ & & \\
\hline $\begin{array}{l}\text { Less than } 25 \\
\text { years }\end{array}$ & 61.5 & 38.5 & 4392 & 62.3 & 37.7 & 2476 & 56.4 & 43.6 & 2443 \\
\hline $25-34$ & 65.6 & 34.4 & 3069 & 66.9 & 33.1 & 1774 & 58.7 & 41.3 & 1971 \\
\hline 35 or above & 65.2 & 34.8 & 3186 & 66.9 & 33.1 & 1838 & 63.2 & 36.8 & 2000 \\
\hline $\begin{array}{lll}\underset{* * *}{\text { Age }} & \text { at } & \text { ma } \\
\end{array}$ & arriag & coh & jitation & NS & & & $*$ & & \\
\hline Less than 15 & 70.5 & 29.5 & 345 & 64.1 & 35.9 & 414 & 58.0 & 42.0 & 582 \\
\hline $15-17$ & 69.4 & 30.6 & 1010 & 66.2 & 33.8 & 1368 & 58.4 & 41.6 & 2192 \\
\hline $18-20$ & 74.8 & 25.2 & 683 & 68.3 & 31.7 & 879 & 59.2 & 40.8 & 1439 \\
\hline 21 and above & 61.1 & 38.9 & 6487 & 64.2 & 35.8 & 2115 & 64.1 & 35.9 & 874 \\
\hline \multicolumn{4}{|c|}{ Number of children borne NS } & NS & & & NS & & \\
\hline None & 63.6 & 36.4 & 2957 & 63.8 & 36.2 & 1828 & 58.2 & 41.8 & 1842 \\
\hline One & 64.6 & 35.4 & 1350 & 65.4 & 34.6 & 850 & 61.1 & 38.9 & 1026 \\
\hline Two & 63.1 & 36.9 & 1815 & 66.0 & 34.0 & 1168 & 60.3 & 39.7 & 1406 \\
\hline Three & 65.2 & 34.8 & 1522 & 65.5 & 34.5 & 920 & 58.0 & 42.0 & 954 \\
\hline Four & 63.8 & 36.2 & 1093 & 66.0 & 34.0 & 575 & 60.5 & 39.5 & 566 \\
\hline Five or more & 63.0 & 37.0 & 1909 & 64.8 & 35.2 & 747 & 57.6 & 42.4 & 620 \\
\hline Education & $* * *$ & & & $* *$ & & & NS & & \\
\hline No e & 60.7 & 39.3 & 5637 & 62.6 & 37.4 & 2403 & 58.4 & 41.6 & 2144 \\
\hline Primary & 67.7 & 32.3 & 1876 & 68.1 & 31.9 & 1068 & 61.5 & 38.5 & 1069 \\
\hline $\begin{array}{l}\text { Secondary or } \\
\text { above }\end{array}$ & 66.9 & 33.1 & 3134 & 66.0 & 34.0 & 2617 & 59.0 & 41.0 & 3201 \\
\hline Religion & $* * *$ & & & $* * *$ & & & $* * *$ & & \\
\hline Hinc & 63.0 & 3 & 9070 & 64.9 & J. & 5160 & 58.6 & 41.4 & 5500 \\
\hline Buddhi & 70.8 & 29.2 & 927 & 71.4 & 28.6 & 511 & 70.8 & 29.2 & 347 \\
\hline Islam & 56.0 & 44.0 & 376 & 45.5 & 54.5 & 202 & 48.3 & 51.7 & 312 \\
\hline $\begin{array}{l}\text { Kirat/Christia } \\
\mathrm{n}\end{array}$ & 77.1 & 22.9 & 275 & 70.7 & 29.3 & 216 & 69.9 & 30.1 & 256 \\
\hline Place of & $* * *$ & & & $* * *$ & & & $*$ & & \\
\hline Urban & 71.0 & 29 & 1640 & 72.4 & 27.6 & 836 & 60.4 & 39.6 & 4029 \\
\hline Rural & 62.5 & 37.5 & 9008 & 63.8 & 36.2 & 5252 & 57.3 & 42.7 & 2385 \\
\hline $\begin{array}{l}\text { Currently } \\
\text { working }\end{array}$ & $* * *$ & & & $*$ & & & $*$ & & \\
\hline No & 60.4 & 39.6 & 3065 & 61.8 & 38.2 & 2360 & 56.4 & 43.6 & 2737 \\
\hline Yes & 65.1 & 34.9 & 7582 & 67.1 & 32.9 & 3727 & 61.4 & 38.6 & 3677 \\
\hline Wea & $* * *$ & & & $* *$ & & & **** & & \\
\hline Poc & 63.2 & 36.8 & 4001 & 65.0 & 50.0 & 2175 & 62.8 & 37.2 & 2318 \\
\hline Middle & 57.7 & 42.3 & 2184 & 61.4 & 38.6 & 1265 & 51.0 & 49.0 & 1317 \\
\hline
\end{tabular}


Prevalence and Determinants of Anaemia among Women aged 15-49 in Nepal

\begin{tabular}{|c|c|c|c|c|c|c|c|c|c|}
\hline Rich & 67.2 & 32.8 & 4461 & 66.7 & 33.3 & 2647 & 60.2 & 39.8 & 2779 \\
\hline \multicolumn{4}{|c|}{$\begin{array}{l}\text { Women's autonomy in household } \\
\text { decision } * * *\end{array}$} & $* * *$ & & & NS & & \\
\hline No autonomy & 60.1 & 39.9 & 4811 & 61.8 & 38.2 & 2607 & 57.7 & 42.3 & 2820 \\
\hline $\begin{array}{l}\text { Moderate } \\
\text { autonomy }\end{array}$ & 68.0 & 32.0 & 2433 & 67.8 & 32.2 & 1435 & 60.2 & 39.8 & 1716 \\
\hline $\begin{array}{l}\text { High } \\
\text { autonomy }\end{array}$ & 66.0 & 34.0 & 3403 & 67.1 & 32.9 & 2046 & 60.6 & 39.4 & 1878 \\
\hline Smoking & $* * *$ & & & $* * *$ & & & $* * *$ & & \\
\hline & 62.0 & 38.0 & 8560 & 64.1 & 35.9 & 5244 & 58.1 & 41.9 & 5841 \\
\hline Yes & 71.2 & 28. & 2088 & 70 & 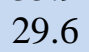 & 44 & 71 & & 573 \\
\hline $\begin{array}{l}\text { Exposure to } \\
\text { newspaper }\end{array}$ & $* * *$ & & & $* * *$ & & & $*$ & & \\
\hline No exposure & 60.7 & 39.3 & 7280 & 63.7 & 36.3 & 3933 & 58.3 & 41 & 4466 \\
\hline Low exposure & 69.0 & 31.0 & 2271 & 63.6 & 36.4 & 1390 & 60.9 & 39.1 & 1413 \\
\hline $\begin{array}{l}\text { High } \\
\text { exposure }\end{array}$ & 73.5 & 26.5 & 1090 & 74.4 & 25.6 & 765 & 63.2 & 36.8 & 535 \\
\hline $\begin{array}{l}\text { Exposure to } \\
\text { radio }\end{array}$ & $* * *$ & & & $* *$ & & & $* * *$ & & \\
\hline No exposure & 53.4 & 46.6 & 1092 & 60.6 & 39.4 & 1102 & 55.4 & 44.6 & 2828 \\
\hline Low exposure & 64.1 & 35.9 & 3101 & 65.0 & 35.0 & 2254 & 62.6 & 37.4 & 1820 \\
\hline $\begin{array}{l}\text { High } \\
\text { exposure }\end{array}$ & 65.4 & 34.6 & 6453 & 66.8 & 33.2 & 2732 & 61.9 & 38.1 & 1766 \\
\hline $\begin{array}{l}\text { Exposure to } \\
\text { TV }\end{array}$ & $* * *$ & & & $* *$ & & & NS & & \\
\hline No exposure & 59.4 & 40.6 & 3014 & 62.8 & 37.2 & 1523 & 60.0 & 40.0 & 1860 \\
\hline Low exposure & 63.9 & 36.1 & 3576 & 63.3 & 36.7 & 1686 & 58.2 & 41.8 & 1325 \\
\hline $\begin{array}{l}\text { High } \\
\text { exposure }\end{array}$ & 66.9 & 33.1 & 4057 & 67.2 & 32.8 & 2879 & 59.2 & 40.8 & 3229 \\
\hline Tota & 63.8 & 36.2 & $\begin{array}{l}1064 \\
7\end{array}$ & 65.0 & 35.0 & 6088 & 59.2 & 40.8 & 6414 \\
\hline
\end{tabular}

Note: $* * *=$ Significant in chi-square test at $\mathrm{p}<0.001 ; * *=\mathrm{p}<0.01$ and $*=\mathrm{p}<0.05 ; \mathrm{NS}=$ Not Significant

Interestingly, women who had smoking habits were less vulnerable to have anaemia. All three NDHS showed that the trends of anaemia prevalence were more among women who did not smoke compared to smokers $(\mathrm{p}<0.001)$. Exposure to mass media was also significantly associated with the prevalence of anaemia. Women having high exposure to newspapers were less prone to be anaemic than the women having low or no exposure to newspaper. In the same way, women who had no exposure to the radio were more prone to be anaemic compared to those who listened to the radio $(\mathrm{p}<0.01)$. Surprisingly, anaemia prevalence was in increasing trend among women who watched TV less than once a week i.e. 36, 37, and 42 per cent in the NDHS 2006, 2011, and 2016 respectively.

\section{Predictors of anaemia prevalence among the WRA}

Women who participated in NDHS 2016 were almost 24 per cent more likely to have anaemia compared to women in NDHS 2006 (aOR $=1.24, \mathrm{p}<0.001)$. So the data showed the worsening condition of women in terms of anaemia prevalence in 2016 than 2006. The higher the age of women, the lower was the chances of anaemia. Women aged 
Prevalence and Determinants of Anaemia among Women aged 15-49 in Nepal

more than 24 years were 13 to 14 per cent less likely to have anaemia than the women aged less than 25 years $(\mathrm{p}<0.01)$.

Women who had primary level education were significantly less likely to have anaemia compared to those who had no formal education $(\mathrm{aOR}=0.79, \mathrm{p}<0.001)$. In the same way, Buddhist, Kirat and Christian women were 28 to 34 per cent less likely to be anaemic compared to those who belonged to the Hindu $(\mathrm{p}<0.001)$ religion. Likewise, rural women were more likely to have anaemia compared to urban women $(\mathrm{aOR}=1.13$, $\mathrm{p}<0.05)$ [Table 3].

Table 3

Adjusted odd ratio (aOR) and 95\% confidence interval (CI) for having anaemia among women aged 15-49 years

\begin{tabular}{|c|c|c|c|c|c|c|}
\hline \multirow[b]{2}{*}{ Selected predicators } & \multicolumn{3}{|l|}{ Model I } & \multicolumn{3}{|l|}{ Model II } \\
\hline & aOR & \multicolumn{2}{|c|}{$95 \% \mathrm{CI}$} & aOR & $\begin{array}{l}95 \% \mathrm{Cl} \\
\text { Lower }\end{array}$ & Upper \\
\hline \multicolumn{7}{|l|}{ Year } \\
\hline NDHS 2006 (ref.) & 1.00 & & & 1.00 & & \\
\hline NDHS 2011 & 0.95 & 0.887 & 1.012 & 1.004 & 0.917 & 1.100 \\
\hline NDHS 2016 & $1.21 * * *$ & 1.137 & 1.291 & $1.236 * * *$ & 1.105 & 1.383 \\
\hline \multicolumn{7}{|l|}{ Age group } \\
\hline Less than 25 years (ref.) & & & & 1.00 & & \\
\hline $25-34$ & & & & $0.860 * *$ & 0.786 & 0.942 \\
\hline 35 or above & & & & $0.872 * *$ & 0.788 & 0.964 \\
\hline \multicolumn{7}{|c|}{$\begin{array}{ll}\text { Age at } \\
\text { cohabitation }\end{array}$ marriage, } \\
\hline Less than 15 (ref.) & & & & 1.00 & & \\
\hline $15-17$ & & & & 0.935 & 0.817 & 1.070 \\
\hline $18-20$ & & & & 0.960 & 0.831 & 1.110 \\
\hline 21 and above & & & & 1.086 & 0.949 & 1.242 \\
\hline \multicolumn{7}{|l|}{$\overline{\text { Education }}$} \\
\hline No education (ref.) & & & & 1.00 & & \\
\hline Primary & & & & $0.791 * * *$ & 0.716 & 0.874 \\
\hline Secondary or above & & & & 0.993 & 0.889 & 1.110 \\
\hline \multicolumn{7}{|l|}{ Religion } \\
\hline Hindu (ref.) & & & & 1.00 & & \\
\hline Buddhist & & & & $0.717 * * *$ & 0.621 & 0.827 \\
\hline Islam & & & & 0.936 & 0.797 & 1.099 \\
\hline Kirat/Christian & & & & $0.661 * * *$ & 0.532 & 0.822 \\
\hline \multicolumn{7}{|l|}{ Place of residence } \\
\hline Urban (ref.) & & & & 1.00 & & \\
\hline Rural & & & & $1.127 *$ & 1.029 & 1.234 \\
\hline \multicolumn{7}{|l|}{ Currently working } \\
\hline No (ref.) & & & & 1.00 & & \\
\hline Yes & & & & 0.939 & 0.870 & 1.013 \\
\hline \multicolumn{7}{|l|}{ Wealth index } \\
\hline Poor (ref.) & & & & 1.00 & & \\
\hline Middle & & & & $1.108 *$ & 1.009 & 1.218 \\
\hline Rich & & & & $0.907 *$ & 0.822 & 1.000 \\
\hline \multicolumn{7}{|c|}{ Women's autonomy in household decision } \\
\hline No autonomy (ref.) & & & & 1.00 & & \\
\hline Moderate autonomy & & & & $0.893 *$ & 0.818 & 0.975 \\
\hline
\end{tabular}


Prevalence and Determinants of Anaemia among Women aged 15-49 in Nepal

\begin{tabular}{|c|c|c|c|c|}
\hline High autonomy & & 0.936 & 0.860 & 1.018 \\
\hline Smoking & & & & \\
\hline No (ref.) & & 1.00 & & \\
\hline Yes & & $0.708 * * *$ & 0.643 & 0.781 \\
\hline Exposure to newspaper & & & & \\
\hline No exposure (ref.) & & 1.00 & & \\
\hline Low exposure & & 0.975 & 0.877 & 1.084 \\
\hline High exposure & & $0.821 *$ & 0.702 & 0.959 \\
\hline Exposure to radio & & & & \\
\hline No exposure (ref.) & & 1.00 & & \\
\hline Low exposure & & $0.851 * *$ & 0.774 & 0.936 \\
\hline High exposure & & $0.831 * * *$ & 0.754 & 0.915 \\
\hline Exposure to TV & & & & \\
\hline No exposure (ref.) & & 1.00 & & \\
\hline Low exposure & & 1.055 & 0.963 & 1.155 \\
\hline High exposure & & 0.976 & 0.883 & 1.079 \\
\hline Constant & $0.567 * * *$ & $0.644 * * *$ & & \\
\hline Cox \& Snell R Square & 0.002 & 0.046 & & \\
\hline -2 Log likelihood & 30493.9 & 20199.6 & & \\
\hline
\end{tabular}

Similarly, women having middle-level wealth status were 11 per cent more likely to have anaemia but women having rich wealth status were nine per cent less likely to be anaemic compared to poor women $(\mathrm{p}<0.05)$. Women with a moderate level of autonomy in household's decision making were less likely to have anaemia compared to those with no autonomy in household decision making ( $\mathrm{aOR}=0.89, \mathrm{p}<0.05)$. Interestingly, women who used to smoke tended to be less likely to have anaemia than who did not smoke $(\mathrm{aOR}=0.71, \mathrm{p}<0.001)$.

Adequate, accurate, relevant, and timely information are vital for decision making for health-related behaviour change (Kreps et al., 2017). Mostly health related information can be obtained from mass media. Exposure to mass media especially exposure to radio was the significant predictor for anaemia prevalence [Table 3]. Data showed that the women who had low or high-level exposure to radio were 15 to 17 per cent less likely to have anaemia compared to those who had no exposure $(\mathrm{p}<0.01)$.

\section{Discussion}

Some results appeared similar in bivariate and multivariate analysis. Background characteristics of women especially age, age at marriage (in NDHS 2006 and NDHS 2016), education (in NDHS 2006 and NDHS 2011), religion, place of living, women's employment, wealth status, women's autonomy in decision making (in NDHS 2006 and NDHS 2011), smoking habit, exposure to media (except exposure to TV in NDHS 2016), were significantly associated with the prevalence of anaemia. Age of women, place of living, wealth status, smoking habit, exposure to radio were significant predictors for having anaemia. Similarly, the educational level of women, religion, women's autonomy in household decision making, and exposure to newspapers were also predictors to some extent.

Comparing our results with other past studies, considerable variations can be observed in terms of some similarities and some differences. A study showed similar results that women residing in rural areas were eight per cent more likely to have anaemia compared to those who lived in urban areas and non-Hindu women were less 


\section{Prevalence and Determinants of Anaemia among Women aged 15-49 in Nepal}

likely to have anaemia compared to Hindu women (Harding et al., 2017). A hospitalbased study in Jumla [Karnali], Nepal also presented similar results that women aged less than 20 years were observed to be more likely to have anaemia compared to women aged more than 20 years(Sharma et al., 2020). Another study from India also showed nearly comparable results that illiterate women were more than literate, rural women more than urban, Hindu women more than women of other religions, and poor women more than rich were more likely to be anaemic(Bharati et al., 2019).

An Ethiopian study showed different results that higher the age, higher chances of anaemia prevalence. Women aged 36-45 years tended to be 4.5 times more likely to have anaemia compared to women aged 15-35 years. But the study also showed similar results that rural women and illiterate women were observed as more likely to have anaemia (Hailu et al., 2019). A cross-sectional study conducted in Ghana showed that more than half (56\%) women were anaemic and most common (73\%) among adolescents aged 15-19 years (Tibambuya et al., 2019). Some similar and some different results were observed in Congo that women aged less than 20 years compared to women more than 20 years and urban women than rural were more likely to have anaemia(Kandala et al., 2019).

Contradictory to the findings of this study, a study in Jordan showed that women who resided in urban areas were 17 per cent more likely to have anaemia compared to those who lived in rural areas(Arabyat et al., 2019). Likewise, a different result was observed in the study from 30 Sub-Saharan African Countries that women who lived in semi-urban or urban areas had significantly higher odds (1.18 to 1.43) of concurrent overweight or obesity and anaemia compared to those women who lived in rural areas (Rhodes et al., 2020). However similar result was noticed that smoker women were less likely to have anaemia prevalence (Arabyat et al., 2019). A cross-sectional study showed different results that women aged 20 to 29 years were more anaemic than women aged less than 20 years and more than 29 years. In the same way, women having school level education were more anaemic than those women who had no formal schooling or graduated women (Kumari et al., 2019). Both results were different from the result of our study.

Likewise, women aged less than 40 years were less likely to be anaemic compared to women aged 40 or more (Kofie et al., 2019). Another study from Ethiopia showed contradictory results that women aged 20 or more years who were attending antenatal care in public hospitals were more likely to have anaemia compared to women aged less than 20 years (Gudeta et al., 2019) but another study in Ethiopia supports the results that rural women attending the hospital were six times more likely of having anaemia compared to those who lived in urban area $[\mathrm{aOR}=6,95 \% \mathrm{CI}=1.3-27.6$, $\mathrm{p}<0.05$ ) (Berhe et al., 2019). Younger aged [15-24] women had higher chances of having anaemia than women aged 35-49 years. Two-third (67\%) of the pregnant women resided in rural areas than those women who lived in urban areas (49\%) were anaemic in Ghana (Ayensu et al., 2020).

More than one third (36\%) of the rural WRA were anaemic compared to 27 per cent of urban women, 42 per cent poorest compared to 27 per cent richest women $(\mathrm{p}<0.001)$ in Uganda which is similar to the findings of our study but younger women were comparatively less anaemic than adult women which is the different result (Nankinga \& Aguta, 2019). Surprisingly, smokers and past smokers were less likely to have anaemia prevalence compared to non-smoker in Japan (Hisa et al., 2019)which is similar with the results of this study. A study from Pakistan also showed similar results that two-third of total illiterate pregnant women were anaemic compared to literate women $(55 \%)$ and women with secondary or higher education (47\%). In the same way, 


\section{Prevalence and Determinants of Anaemia among Women aged 15-49 in Nepal}

63 per cent of total rural pregnant women were anaemic compared to 53 per cent of urban women (Ullah et al., 2018).

Various studies support our findings that younger age, rural residency, nonsmoker are some predictors for having a higher prevalence of anaemia among reproductive-aged women (Gautam et al., 2019). Prevalence of anaemia varies in different places and persons with a particular condition but is most common in younger, poor and pregnant women (Tulu et al., 2019). Another study showed age and ethnicity of women were the significant predictors of anaemia prevalence (Aljaadi et al., 2019). Rural women who went for antenatal appointments were noticed more likely to have anaemia than those who resided in urban areas in Ethiopia (Belay et al., 2019; Samuel et al., 2020).

It was noticed that media exposure was significantly associated with the prevalence of anaemia. High exposure to media was associated with lower chances of anaemia. An experimental study conducted in Jordan using a health information package programme showed 24 and 54 per cent of the pregnant women were non-anaemic respectively in control and experimental groups (Abujilban et al., 2018). In the same way, a quasi-experimental study conducted in Indonesia showed that health education and counselling through pictorial handbooks had a positive impact on pregnant women (Nahrisah et al., 2020). So, exposure to communication and information about healthrelated issues may be a vital tool to reduce anaemia prevalence among the WRA.

Wealth status was noticed as a significant predictor for anaemia prevalence in this study. Women with middle-level wealth status were almost 11 per cent more likely to have anaemia prevalence but women having rich wealth status were as nearly as nine per cent less likely to have anaemia compared to the women who had poor wealth status. Similar to this finding, a study from Rwanda showed that women belonging to middle and rich wealth status were 17 and 26 per cent less likely to be anaemic compared to poor women respectively (Hakizimana et al., 2019). Women having formal education tended to be less likely to have anaemia prevalence in Ethiopia compared to those women who had no formal education which was similar to this study (Samuel et al., 2020).

\section{Strengths and limitations of the study}

The study has several strengths in terms of sample size, sampling procedure, and data from three different surveys on a periodic basis. It uses secondary data from recent three NDHSs data. The data were representative of the whole nation in all NDHSs. The data were merged for multivariate analysis. We analysed the data in three ways, univariate and bivariate analysis separately for all three NDHSs and multivariate analysis in a combined way. The study also had some limitations. The nature of data was quantitative, so qualitative aspects and issues of women were missed. The study uses a cross-sectional design; therefore, it is difficult to detect root cause analysis beyond cause and effect relationships. We included the wealth status of women by assessing proxy measures of household assets and consumption patterns. Some patterns of data have been changed in previous and recent NDHS such as boundaries and numbers of rural and urban areas, and number of sample taken from the areas. We assessed limited variables based on the literature available and the objectives of the study.

\section{Conclusion}

Although the prevalence of severe anaemia remained static, the prevalence of mild and moderate anaemia stepped up making the situation worse throughout the decade (2006 to 2016). Overall, 41 per cent of WRA were anaemic in 2016 compared to 


\section{Prevalence and Determinants of Anaemia among Women aged 15-49 in Nepal}

$36 \%$ in 2006. Socio-demographic characteristics such as age group of women, religion, place of residence, working status, wealth index, smoking habit, exposure to newspapers and radio were significantly associated with the prevalence of anaemia among the WRA. Nearly similar results were observed in the multivariate analysis. It showed that the age group of women, place of residence, wealth index, smoking habit, and exposure to radio were significant predictors for having anaemia. Policymakers need to re-evaluate and amend the existing policies and programmes since these programmes seemed not so effective in reducing the prevalence of anaemia. Moreover, policies and programmes need to target comparatively more vulnerable populations.

\section{Acknowledgements}

The authors would like to thank MEASURES DHS/DHS program for providing access to NDHS datasets.

\section{References}

Abujilban, S., Hatamleh, R., \& Al-Shuqerat, S. (2018). The impact of a planned health educational program on the compliance and knowledge of Jordanian pregnant women with anemia. Women \& Health, 1-12. https://doi.org/10.1080/03630242.2018.1549644

Abusharib, A. B. (2019). Morphological patterns of anaemia among pregnant women from Sudan. African Journal of Laboratory Medicine, 8(1), 1-7. https://doi.org/10.4102/ajlm.v8i1.743

Ajepe, A. A., Okunade, K. S., Sekumade, A. I., Daramola, E. S., Beke, M. O., Ijasan, O., Olowoselu, O. F., \& Afolabi, B. B. (2020). Prevalence and foetomaternal effects of iron deficiency anaemia among pregnant women in Lagos, Nigeria. PLoS ONE, 5(1), 1-13. https://doi.org/10.1371/journal.pone.0227965

Aljaadi, A. M., How, R. E., Loh, S. P., Hunt, S. E., Karakochuk, C. D., Barr, S. I., Mcanena, L., Ward, M., Mcnulty, H., Khor, G. L., Devlin, A. M., \& Green, T. J. (2019). Suboptimal Biochemical Riboflavin Status Is Associated with Lower Hemoglobin and Higher Rates of Anemia in a Sample of Canadian and Malaysian Women of Reproductive Age. The Journal of Nutrition, 1-8. https://doi.org/10.1093/jn/nxz151.

Ampiah, M. K. M., Kovey, J. J., Apprey, C., \& Annan, R. A. (2019). Comparative analysis of trends and determinants of anaemia between adult and teenage pregnant women in two rural districts of Ghana. BMC Public Health, 19(1379), 1-9. https://doi.org/10.1186/s12889-019-7603-6

Arabyat, R., Arabyat, G., \& Al-taani, G. (2019). Prevalence and risk factors of anaemia among ever-married women in Jordan. East Mediterr Health Journal, 25(8), 543-552. https://doi.org/10.26719/emhj.18.074

Ayensu, J., Annan, R., Lutterodt, H., Edusei, A., \& Peng, L. S. (2020). Prevalence of anaemia and low intake of dietary nutrients in pregnant women living in rural and urban areas in the Ashanti region of Ghana. PLoS ONE, 5(1), 1-15. https://doi.org/10.1371/journal.pone.0226026

Belay, A. M. H., Tariku, A., Woreta, S. A., Debalkie, G., \& Asrade, G. (2019). Anemia and associated factors among pregnant women attending prenatal care in rural Dembia district, North West Ethiopia: A cross-sectional study. Ecology of Food and Nutrition, 1-21. https://doi.org/10.1080/03670244.2019.1680551

Berhe, B., Mardu, F., Legese, H., Gebrewahd, A., Gebremariam, G., Tesfay, K., Kahsu, G., Negash, H., \& Adhanom, G. (2019). Prevalence of anemia and associated 


\section{Prevalence and Determinants of Anaemia among Women aged 15-49 in Nepal}

factors among pregnant women in Adigrat General Hospital, Tigrai, northern Ethiopia, 2018. BMC Research Notes, 12(310), 1-6. https://doi.org/10.1186/s13104-019-4347-4

Bharati, S., Pal, M., Sen, S., \& Bharati, P. (2019). Malnutrition and anaemia among adult women in India. Journal of Biosocial Science, $X, 1-11$. https://doi.org/10.1017/S002193201800041X

Department of Health Services. (2019). Annual Report: Department of Health Services 2074/75 (2017/18). content/uploads/2019/07/Annual_Report_2074-751.pdf

Ford, N. D., Padarth, R., Kedar, B., Parajuli, R., Paudyal, N., Joshi, N., Whitehead, R. D., Chitekwe, S., Mei, Z., Flores-Ayala, R., Adhikari, D. P., Rijal, S., \& Jefferds, M. E. (2020). Factors associated with anaemia in a nationally representative sample of nonpregnant women of reproductive age in Nepal. Maternal \& Child Nutrition, e12953, 1-11. https://doi.org/10.1111/mcn.12953

Gautam, S., Min, H., Kim, H., \& Jeong, H. (2019). Determining factors for the prevalence of anemia in women of reproductive age in Nepal: Evidence from recent national survey data. PLoS ONE, 14(6), 1-17. https://doi.org/10.1371/ journal.pone.0218288

Grover, K., Kumar, T., Doda, A., Bhutani, R., Yadav, S., Kaushal, P., Kapoor, R., \& Sharma, S. (2020). Prevalence of anaemia and its association with dietary habits among pregnant women in the urban area of Haryana. Journal of Family Medicine and Primary Care, 9(2), 783-787. https://doi.org/10.4103/jfmpc.jfmpc

Gudeta, T. A., Regassa, T. M., \& Belay, A. S. (2019). Magnitude and factors associated with anemia among pregnant women attending antenatal care in Bench Maji, Keffa and Sheka zones of public hospitals, Southwest, Ethiopia, 2018: A cross sectional study. Plos ONE, 14(11), 30-34. https://doi.org/10.1371/journal.pone.0225148

Hailu, T., Kassa, S., Abera, B., Mulu, W., \& Genanew, A. (2019). Determinant factors of anaemia among pregnant women attending antenatal care clinic in Northwest Ethiopia. Tropical Diseases, Travel Medicine and Vaccines, 5(13), 1-7. https://doi.org/10.1186/s40794-019-0088-6

Hakizimana, D., Nisingizwe, M. P., Logan, J., \& Wong, R. (2019). Identifying risk factors of anemia among women of reproductive age in Rwanda - a crosssectional study using secondary data from the Rwanda Demographic and Health Survey 2014 / 2015. BMC Public Health, 19(1662), 1-11. https://doi.org/10.1186/s12889-019-8019-z

Harding, K. L., Aguayo, V. M., Namirembe, G., \& Webb, P. (2017). Determinants of anemia among women and children in Nepal and Pakistan: An analysis of recent national survey data. Maternal and Child Nutrition, e12478, 1-13. https://doi.org/10.1111/mcn. 12478

Herzog, S. A., Leikauf, G., Jakse, H., Siebenhofer, A., Haeusler, M., \& Berghold, A. (2019). Prevalence of anemia in pregnant women in Styria, Austria: A retrospective analysis of mother-child examinations 2006-2014. PLOS ONE, 14(7), 1-10. https://doi.org/10.1371/journal. pone.0219703

Hisa, K., Haruna, M., Hikita, N., Sasagawa, E., Yonezawa, K., Suto, M., \& Ota, E. (2019). Prevalence of and factors related to anemia among Japanese adult women: Secondary data analysis using health check-up database. Scientific Reports, 9(17048), 1-8. https://doi.org/10.1038/s41598-019-52798-y

Jamnok, J., Sanchaisuriya, K., Sanchaisuriya, P., Fucharoen, G., Fucharoen, S., \& Ahmed, F. (2020). Factors associated with anaemia and iron deficiency among 


\section{Prevalence and Determinants of Anaemia among Women aged 15-49 in Nepal}

women of reproductive age in Northeast Thailand: A cross-sectional study. BMC Public Health, 20(102), 1-8. https://doi.org/10.1186/s12889-020-8248-1

Kandala, N. I., Pallikadavath, S., Channon, A. A., Knight, G., \& Madise, N. J. (2019). A multilevel approach to correlates of anaemia in women in the Democratic Republic of Congo: Findings from a nationally representative survey. European Journal of Clinical Nutrition, 1-12. https://doi.org/10.1038/s41430-019-0524-8

Kay, A., Leidman, E., Lopez, V., Wilkinson, C., Tondeur, M., \& Bilukha, O. (2019). The burden of anaemia among displaced women and children in refugee settings worldwide, 2013 - 2016. BMJ Global Health, 4(e001837), 1-10. https://doi.org/10.1136/bmjgh-2019-001837

Kofie, P., Tarkang, E. E., Manu, E., Amu, H., Ayanore, M. A., Aku, F. Y., Komesuor, J., Adjuik, M., Binka, F., \& Kweku, M. (2019). Prevalence and associated risk factors of anaemia among women attending antenatal and post-natal clinics at a public health facility in Ghana. BMC Nutrition, 5(40), 1-9. https://doi.org/10.1186/s40795-019-0303-x

Kreps, G. L., Yu, G., Zhao, X., Chou, S. W., \& Hesse, B. (2017). Expanding the NCI health information national trends survey from the United States to China and beyond: Examining the influences of consumer health information needs and practices on local and global health. Journalism \& Mass Communication Quarterly, 1-11. https://doi.org/10.1177/1077699016687725

Kumari, S., Garg, N., Kumar, A., Kumar, P., Guru, I., Ansari, S., Anwar, S., Pratap, K., Kumari, P., Kumar, P., Kumar, B., Nehar, S., \& Kumar, A. (2019). Maternal and severe anaemia in delivering women is associated with risk of preterm and low birth weight: A cross sectional study from Jharkhand, India. One Health, 8(August), 100098. https://doi.org/10.1016/j.onehlt.2019.100098

Miles, L. F., Larsen, T., Bailey, M. J., Burbury, K. L., Story, D. A., \& Bellomo, R. (2019). Borderline anaemia and postoperative outcome in women undergoing major abdominal surgery: A retrospective cohort study. Anaesthesia, September, 1-8. https://doi.org/10.1111/anae.14870

Ministry of Health and Population (MOHP) [Nepal], New ERA, ICF International Inc., \& Macro International Inc. (2012). Nepal Demographic and Health Survey 2011. https://dhsprogram.com/pubs/pdf/FR191/FR191.pdf

Ministry of Health and Population (MOHP) [Nepal], New ERA, \& Macro International Inc. (2007). Nepal Demographic and Health Survey 2006. https://dhsprogram.com/pubs/pdf/FR191/FR191.pdf

Ministry of Health, New ERA, \& ICF. (2017). Nepal Demographic and Health Survey 2016. www.dhsprogram.com/pubs/pdf/fr336/fr336.pdf

Nahrisah, P., Somrongthong, R., Viriyautsahakul, N., Viwattanakulvanid, P., \& Plianbangchang, S. (2020). Effect of Integrated Pictorial Handbook Education and Counseling on Improving Anemia Status, Knowledge, Food Intake, and Iron Tablet Compliance Among Anemic Pregnant Women in Indonesia: A QuasiExperimental Study. Journal of Multidisciplinary Healthcare, 13, 43-52. https://doi.org/10.2147/JMDH.S213550

Nankinga, O., \& Aguta, D. (2019). Determinants of Anemia among women in Uganda: Further analysis of the Uganda Demographic and Health Surveys. BMC Public Health, 19(1757), 1-9. https://doi.org/10.1186/s12889-019-8114-1

National Planning Commission. (2015). Sustainable Development Goals 2016-2030: National \{Prelinimary\} Report. https://www.undp.org/content/dam/nepal/docs/reports/SDG final reportnepal.pdf 


\section{Prevalence and Determinants of Anaemia among Women aged 15-49 in Nepal}

Neogi, S. B., Devasenapathy, N., Singh, R., Bhushan, H., Shah, D., Divakar, H., Zodpey, S., Malik, S., Nanda, S., Mittal, P., Batra, A., Chauhan, M. B., Yadav, S., Dongre, H., Saluja, S., Malhotra, V., Gupta, A., Sangwan, R., Radhika, A. G., ... Baswal, D. (2019). Safety and effectiveness of intravenous iron sucrose versus standard oral iron therapy in pregnant women with moderate-to-severe anaemia in India: A multicentre, open-label, phase 3, randomised, controlled trial. The Lancet Global Health, 7(12), e1706-e1716. https://doi.org/10.1016/S2214109X(19)30427-9

Nepal Health Research Council. (2011). National ethical guidelines for health research in Nepal and standard operating procedures (Issue January). Nepal Health Research Council.

Okawa, S., Win, H. H., Nanishi, K., Shibanuma, A., Aye, P. P., Saw, T. N., \& Jimba, M. (2019). Advice on healthy pregnancy, delivery, motherhood and information on non- communicable diseases in the maternal care programme in Myanmar: a cross- sectional study. BMJ Open, 9(e025186), 1-10. https://doi.org/10.1136/bmjopen-2018-025186

Rhodes, E. C., Suchdev, P. S., Narayan, K. M. V., Cunningham, S., Weber, M. B., Tripp, K., Mapango, C., Ramakrishnan, U., Hennink, M., \& Williams, A. M. (2020). The co-occurrence of overweight and micronutrient deficiencies or anemia among women of reproductive age in Malawi. The Journal of Nutrition, 1-12. https://doi.org/10.1093/jn/nxaa076

Samuel, S., Darebo, T., Desta, D. T., \& Mulugeta, A. (2020). Socio-economic and dietary diversity characteristics are associated with anemia among pregnant women attending antenatal care services in public health centers of KembataTembaro Zone, Southern Ethiopia. Food Science and Nutrition, January, 1-9. https://doi.org/10.1002/fsn3.1485

Sharma, D., Amgain, K., Panta, P. P., \& Pokhrel, B. (2020). Hemoglobin levels and anemia evaluation among pregnant women in the remote and rural high lands of mid-western Nepal: A hospital based study. BMC Pregnancy and Childbirth, 20(182), 1-7. https://doi.org/10.1186/s12884-020-02870-7

Tibambuya, B. A., Ganle, J. K., \& Ibrahim, M. (2019). Anaemia at antenatal care initiation and associated factors among pregnant women in West Gonja District, Ghana: A cross-sectional study. Pan African Medical Journal, 33(325), 1-11. https://doi.org/10.11604/pamj.2019.33.325.17924

Tulu, B. D., Atomssa, E. M., \& Mengist, H. M. (2019). Determinants of anemia among pregnant women attending antenatal care in Horo Guduru Wollega Zone, West Ethiopia: Unmatched case-control study. PLoS ONE, 14(10), 1-13. https://doi.org/10.1371/journal.pone.0224514

Ullah, A., Sohaib, M., Saeed, F., Iqbal, S., \& Sohaib, M. (2018). Prevalence of anemia and associated risk factors among pregnant women in Lahore, Pakistan. Women \& Health, 1-12. https://doi.org/10.1080/03630242.2018.1544966

Wemakor, A. (2019). Prevalence and determinants of anaemia in pregnant women receiving antenatal care at a tertiary referral hospital in Northern Ghana. BMC Pregnancy and Childbirth, 19(495), 1-11. https://doi.org/10.1186/s12884-0192644-5

Williams, P. A., Poehlman, J., Moran, K., Siddiqui, M., Kataria, I., Rego, A. M., Mehrotra, P., \& Saldanha, N. (2020). Strategies to address anaemia among pregnant and lactating women in India: A formative research study. Public Health Nutrition, 8, 1-11. https://doi.org/10.1017/S1368980019003938 
Prevalence and Determinants of Anaemia among Women aged 15-49 in Nepal

World Health Organization. (2016). WHO recommendations on antenatal care for a positive pregnancy experience. World Health Organization. https://apps.who.int/iris/bitstream/handle/10665/250796/9789241549912eng.pdf? sequence $=1$ 